\title{
HEART RATE VARIABILITY IN WORKERS OF VARIOUS PROFESSIONS IN CONTRASTING SEASONS OF THE YEAR
}

\author{
ALEXANDER MARKOV, IURIY SOLONIN, and EVGENIY BOJKO \\ Komi Science Center, The Ural Branch of the Russian Academy of Sciences, Syktyvkar, Russia \\ Department of Ecological and Medical Physiology, Institute of Physiology
}

\begin{abstract}
Objectives: It is known that professional occupation affects the heart rate variability (HRV). However, most studies have not taken into account seasonal features of the HRV. The aim of this study has been to evaluate the HRV differences in winter and in summer in the case of the Ministry of the Russian Federation for Civil Defense, Emergencies and Elimination of Consequences of Natural Disasters (EMERCOM) workers and scientific workers from the Komi Science Center of the Ural Branch of the Russian Academy of Sciences. Material and Methods: The short-term HRV was examined for 13 EMERCOM workers and 13 scientific workers. The data was collected in winter (December) and summer (July) for the same groups of workers. The time domain and frequency domain HRV analyses were performed. The EMERCOM workers had more contact with the external environment than the scientific workers. Results: The two-way analysis of variance with repeated observations on a single factor has shown that "Season" and interaction of two factors "Season" and "Profession" significantly influenced the HRV among volunteers. The "Profession" factor did not influence the HRV parameters (except for the heart rate in winter, $\mathrm{p}=0.042$ ). Seasonal changes in the HRV parameters were not significant in the case of scientific workers. In contrast, the EMERCOM workers showed significantly decreased parameters of parasympathetic activity (the root-mean-square of successive differences in RR intervals, percentage of consecutive RR intervals differing by $>50 \mathrm{~ms}$ and the relative value high frequency power, $\mathrm{p}=0.001, \mathrm{p}=0.014$ and $\mathrm{p}=0.009$, respectively) and increased parameters of sympathetic activity (the stress index and ratio of low-frequency power to high-frequency power, $p=0.012$ and $p=0.006$, respectively) in winter as compared to summer. Conclusions: The results of our study indicate that, unlike the scientific workers, the EMERCOM workers showed significant changes in the HRV in contrasting seasons (winter and summer). A season of a year should be considered when assessing the HRV among workers of various professions. Int J Occup Med Environ Health 2016;29(5):793-800
\end{abstract}

Key words:

Workers, Heart rate variability, Autonomic nervous function, Environmental factors, Working conditions,

Work environment

\section{INTRODUCTION}

The heart rate variability (HRV) is used as an indicator for the cardiovascular system regulation. It is known that professional occupation affects the HRV. Many authors have studied the HRV among chemical industry workers [1-3], information service workers [4,5], physicians [6], nurses [7], engineers [8], office workers [9-11], and other professional groups. However, all these studies have not taken into account seasonal features of the HRV. Some studies have shown that the HRV parameters vary in different seasons [12-14]. We have assumed that in the case of professional groups with varying contact with external

Received: March 31, 2014. Accepted: October 30, 2015.

Corresponding author: A. Markov, Komi Science Center, The Ural Branch of the Russian Academy of Sciences, Department of Ecological and Medical Physiology, Institute of Physiology, Pervomaiskaya 50,167982 Syktyvkar, Russia (e-mail: volkarb@mail.ru). 
environment, the HRV would vary in different seasons. To investigate the validity of this assumption we have conducted studies during contrasting seasons of the year. Therefore, the aim of the study has been to evaluate the HRV for the Ministry of the Russian Federation for Civil Defense, Emergencies and Elimination of Consequences of Natural Disasters (EMERCOM) workers in Russia and scientific workers in different seasons (winter and summer).

\section{MATERIAL AND METHODS}

\section{Participants}

A group of 13 workers from the EMERCOM and a group of 13 scientific workers from the Komi Science Center of the Ural Branch of the Russian Academy of Sciences were recruited for the study. The data was collected in winter (December, 1st examination) and summer (July, 2nd examination) for the same groups of workers. All the personal observations were performed once (for each individual) in a 5-day period, both in summer and in winter. Measurements were taken between 9:00 a.m. and 12:30 p.m. All subjects were healthy, without chronic disease, current prescription medication or history of cardiovascular disease.

\section{Working conditions}

The scientific workers worked from 8:30 a.m. to 5:30 p.m. and the EMERCOM workers worked from 9:00 a.m. to 6:00 p.m. Working hours in both groups were $40 \mathrm{~h} /$ week. The scientific workers had mostly sedentary work with low physical activity, a large amount of time spent sitting down at a computer. The EMERCOM workers were inspectors. The EMERCOM inspectors performed the safety assessment of industrial facilities and residential property, and initiated accident prevention measures. In comparison with the scientific workers, the EMERCOM workers had a higher physical activity and higher exposure to the external environment. The average time of the environmental exposure during working hours in the case of the EMERCOM inspectors was approx. $3 \mathrm{~h} /$ day and in the case of the scientific workers, it was approx. $30 \mathrm{~min} /$ day.

Information about each participant's job, physical activity, daily habits and duration of environmental exposure was obtained through a questionnaire. Subjects were instructed not to change their physical activity levels during the study.

\section{Environmental factors}

Four environmental factors were measured during the study: indoor and outdoor temperature, relative humidity of the indoor air, and atmospheric pressure. The temperature was measured using a laboratory mercury thermometer TL-4 No. 2 (Novolab, Russia). The relative humidity of the indoor air was measured using a hygrometer M-19 (Granat, Russia). The atmospheric pressure was measured using an aneroid barometer M-67 (Technosbyt, Russia). The Table 1 shows the environmental conditions, to which the subjects were exposed on the days of the study. There were no significant differences in environmental factors between the two groups, both in winter and in summer.

\section{Anthropometry}

Body weight and height were measured and the body mass index (BMI) was computed in terms of the quotient of $\mathrm{kg}$ of the body weight $/ \mathrm{m}^{2}$ height.

\section{Heart rate variability}

Prior to the HRV measurement, subjects rested for 10 min. Subsequently, an electrocardiogram (ECG) was recorded for $5 \mathrm{~min}$ in the sitting position. The ECG recordings were analyzed using the Ecosan-2007 complex (Medical Computer Systems, Russia). The heart rate variability was examined for the following time domain and geometric measures: the standard deviation of normal RR intervals (SDNN), the percentage rate of times a successive RR interval was greater than the previous interval by $>50 \mathrm{~ms}$ (pNN50) and the root-mean-square 
Table 1. Environmental conditions on days of studying the heart rate variability

\begin{tabular}{|c|c|c|c|c|}
\hline \multirow{3}{*}{ Variable } & \multicolumn{4}{|c|}{ Study group } \\
\hline & \multicolumn{2}{|c|}{ winter } & \multicolumn{2}{|c|}{ summer } \\
\hline & $\begin{array}{c}\text { EMERCOM } \\
\text { workers }\end{array}$ & $\begin{array}{c}\text { KSC scientific } \\
\text { workers }\end{array}$ & $\begin{array}{c}\text { EMERCOM } \\
\text { workers }\end{array}$ & $\begin{array}{c}\text { KSC scientific } \\
\text { workers }\end{array}$ \\
\hline \multicolumn{5}{|l|}{ Temperature $\left[{ }^{\circ} \mathrm{C}\right](\mathrm{M} \pm \mathrm{SD})$} \\
\hline indoor & $20.92 \pm 0.90$ & $20.79 \pm 0.97$ & $22.90 \pm 2.33$ & $23.12 \pm 1.46$ \\
\hline outdoor & $-13.33 \pm 6.57$ & $-13.43 \pm 7.32$ & $17.09 \pm 1.92$ & $17.56 \pm 3.14$ \\
\hline Relative humidity of indoor air $[\%](\mathrm{M} \pm \mathrm{SD})$ & $27.92 \pm 3.82$ & $27.71 \pm 5.34$ & $60.08 \pm 9.47$ & $58.68 \pm 7.58$ \\
\hline Atmospheric pressure $[\mathrm{mm} \mathrm{Hg}](\mathrm{M} \pm \mathrm{SD})$ & $756.08 \pm 4.72$ & $757.02 \pm 5.08$ & $745.47 \pm 2.31$ & $746.12 \pm 2.03$ \\
\hline
\end{tabular}

$\mathrm{M}$ - mean; SD - standard deviation.

EMERCOM - Ministry of the Russian Federation for Civil Defense, Emergencies and Elimination of Consequences of Natural Disasters; KSC - Komi Science Center of the Ural Branch of the Russian Academy of Sciences.

of successive differences in RR intervals (RMSSD). The standard deviation of normal RR intervals (SDNN) is an index of the overall HRV and reflects both sympathetic and parasympathetic influences. The pNN50 and RMSSD are viewed as a time-domain-based indices corresponding to parasympathetic neural regulation on the heart. According to the variable pulsometer data widely used in Russia, the index of tension of regulatory systems or stress index (SI) was calculated using the following formula:

$$
\mathrm{SI}=\frac{\mathrm{AMo}}{2 \mathrm{Mo} \times \mathrm{MxDMn}}
$$

where:

Mo - mode, the most frequently observed value in the dynamic line of cardio intervals; in physiological sense - this is the most probable level of cardiovascular functioning,

AMo - the amplitude of a mode is the number of cardio intervals appropriate to Mo value, in \%, and characterizes similarity of values of cardio intervals and reflects stabilizing effect of heart rhythm management, which is caused, basically, by the degree of sympathetic system activation,

MxDMn - the variation scope reflects a degree of variability of cardio interval values in respect of the researched dynamic line and is calculated in terms of the difference of maximum and minimum values of cardio intervals and consequently at arrhythmias or artifact errors, which may be allowed, if the dynamic line of cardio intervals was not subject to preliminary editing; in the case of the calculation of MxDMn, the extreme values of cardio intervals are usually rejected, if they make less than $3 \%$ out of the full amount of an analyzed sample.

Physiological sense of MxDMn is usually connected to activity of the parasympathetic system [15]. The stress index reflects the activity of sympathetic regulatory mechanisms and the status of the central circle of circulation regulation [16]. Additionally, the following frequency domain components of the HRV were examined: low frequency $(\mathrm{LF}=0.04-0.15 \mathrm{~Hz})$, high frequency $(\mathrm{HF}=0.15$ $0.4 \mathrm{~Hz})$, and total power $(\mathrm{TP}=0-0.4 \mathrm{~Hz})$. The total power is regarded as an index of comprehensive autonomic activity. The power spectrum of the HF band is affected by the activity of the vagal nerve, while the power spectrum of the LF band mainly relates to the activity of sympathetic nerve. All frequency domain components were expressed in absolute units $\left(\mathrm{ms}^{2}\right)$ and relative values $(\%)$. Relative powers were calculated in terms of the percentage rates of the total power in each frequency band. The ratio of absolute power in the LF and HF bands ( $\mathrm{LF} / \mathrm{HF}$ ) is considered to be an indicator of sympathetic-parasympathetic balance [17]. 


\section{Ethics}

A written informed consent was obtained from each subject. The study protocol was approved by the local Committee for Bioethics at the Institute of Physiology Komi Science Center of the Ural Branch of the Russian Academy of Sciences.

\section{Statistics}

The data on environmental factors and anthropometry was presented as the mean \pm standard deviation $(\mathrm{M} \pm \mathrm{SD})$. The data on the HRV parameters was presented as the median and 25th and 75th percentiles. The statistical analysis was performed using Statistica 8.0 (StatSoft, Inc., USA). The data distribution was confirmed by the Shapiro-Wilk test. One-way ANOVA was used to assess the differences in environmental conditions, age and body mass index between the two study groups. The two-way analysis of variance with repeated observations, separately on each measured variable, was used to reveal influence of factors "Profession" and "Season" as well as their interaction. Post hoc multiple comparisons were conducted using the Tukey's test. A Spearman correlation test was used to analyze the correlation between the BMI and HRV. P values of $\leq 0.05$ were considered to be statistically significant.

\section{RESULTS}

We observed significant differences in the BMI between the EMERCOM workers and the scientific workers recruited for our study (Table 2). The body mass index was significantly higher for the EMERCOM workers than for the scientific workers $(p<0.05)$. There were no significant age differences between the two groups of volunteers.

In order to further explore the relationships between groups and seasons, a 2-way analysis of variance was performed (Table 3). A significant interaction effect between "Profession" and "Season" was found for the RMSSD, pNN50, stress index (SI), HF (\%), LF (\%), LF/HF ( $<<0.05)$ dependent variables. In addition, there was a significant season effect on the HRV parameters (RMSSD, pNN50, SI, relative $\mathrm{HF}$ value, $\mathrm{LF} / \mathrm{HF}, \mathrm{p}<0.05)$. The "Profession" factor had no effect on the HRV (except for HR, $p<0.05$ ).

In the Table 3 we present the comparisons of the HRV parameters between the two study groups (i.e., the EMERCOM workers and scientific workers) in winter and summer. The HR was only significantly higher in the case of the EMERCOM workers in comparison with the scientific workers in winter $(p=0.042)$. Other HRV parameters in summer and winter showed no significant differences between the two groups of participants.

Seasonal changes of the HRV parameters were not significant in the group of scientific workers. In the case of the EMERCOM workers, however, the HRV parameters were season-dependent. The root-mean-square of successive differences in RR intervals and pNN50 values were significantly lower in winter than in summer $(p=0.001$ and $p=0.014$, respectively). The relative HF value also

Table 2. Characteristics of the study groups

\begin{tabular}{lcccc}
\hline \multirow{2}{*}{ Variable } & \multicolumn{3}{c}{ Study group } \\
\cline { 2 - 5 } & EMERCOM workers & KSC scientific workers & EMERCOM workers & KSC scientific workers \\
\cline { 2 - 5 } & $34.30 \pm 5.58$ & $31.70 \pm 6.78$ & $34.80 \pm 5.83$ & $31.90 \pm 7.26$ \\
Age $[\mathrm{years}](\mathrm{M} \pm \mathrm{SD})$ & $28.47 \pm 2.36$ & $25.46 \pm 3.40^{*}$ & $28.10 \pm 2.52$ & $25.13 \pm 3.75^{*}$ \\
\hline BMI $\left[\mathrm{kg} / \mathrm{m}^{2}\right](\mathrm{M} \pm \mathrm{SD})$ & &
\end{tabular}

BMI - body mass index.

Other abbreviations as in Table 1.

* Compared with EMERCOM workers: $\mathrm{p}<0.05$. 


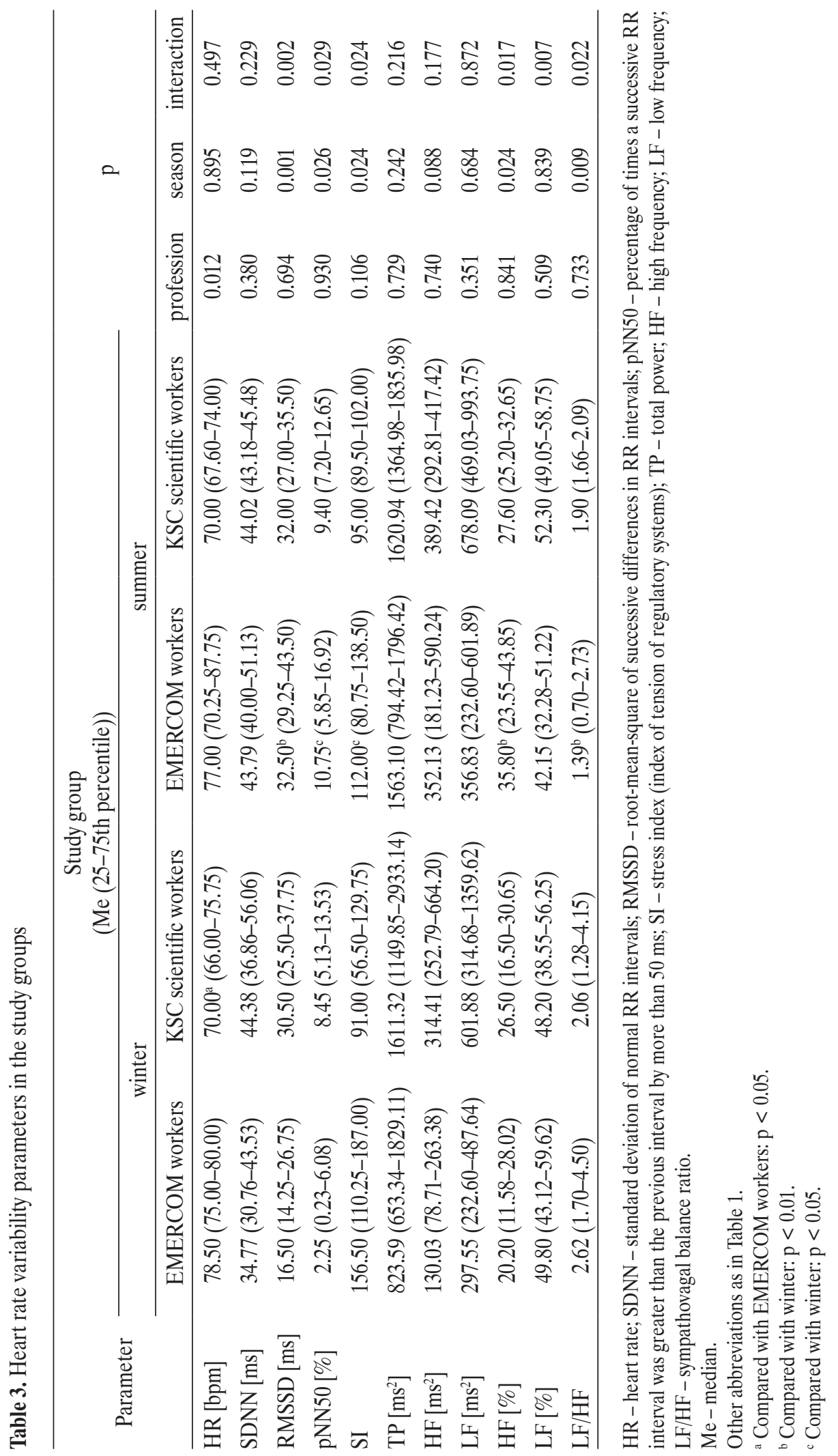


decreased significantly in winter $(p=0.009)$. The stress index and LF/HF increased in winter $(p=0.012$ and $p=0.006$, respectively). There were no significant differences in the HR, SDNN, total power, and absolute values of high and low frequencies power (HF and LF in $\mathrm{ms}^{2}$ ), the relative value of $L F$ between seasons $(p>0.05)$.

\section{DISCUSSION}

The results of our study indicate that a season of the year and the duration of the exposure to the environmental factors affect the heart rate variability (HRV) parameters for men working in various professions.

In our study we observed the EMERCOM workers and scientific workers to have significant differences in the body mass index (BMI). The effect of the BMI on the HRV parameters is still disputed in the literature. A number of studies have found significant correlations between the HRV and BMI $[18,19]$. Several studies have found only weak correlations between the BMI and parameters of the HRV [20,21]. Other studies have found that HRV parameters are independent of the BMI [22,23]. In our study we utilized Spearman's correlation tests to evaluate correlations between the BMI and the HRV parameters. We have found no significant correlations between the HRV parameters and the BMI for volunteers in summer and in winter. Thus, the differences in the HRV parameters between the groups were not associated with the body mass index differences.

The two-way analysis of variance with repeated observations on a single factor has shown that "Season" and interaction of two factors "Season" and "Profession" significantly influenced the HRV among volunteers. The "Profession" factor hardly influenced the HRV.

Some authors have reported seasonal variations in the HRV parameters. Kristal-Boneh et al. (2000) showed that the HRV in winter was less than that in summer even after adjustment for age, serum level of cholesterol, systolic blood pressure and the body mass index [12]. A weak but significant seasonal variation was found for the total power and high-frequency power [13]. Sato el al. (2013) showed that the heart rate variability during sleep was not significantly different between summer and winter [24]. We found that the heart rate did not change significantly between the seasons in either group. In the group of scientific workers, the HR and HRV parameters were roughly at the same level in winter and in summer. In contrast, in the EMERCOM worker group, we observed the significant $\mathrm{HRV}$ parameter variations in contrasting seasons. We observed a significantly lower parasympathetic and a higher sympathetic influence on the heart rate in the case of the EMERCOM workers in winter in comparison with summer (higher LF/HF and lower RMSSD, pNN50 values, absolute value of $\mathrm{HF}$ ).

The index of the regulatory system tension (stress index - SI) characterizes activity of mechanisms of a sympathetic regulation [16]. In the case of the EMERCOM workers, this parameter was significantly higher in winter than in summer $(p<0.05)$. In winter it was also higher than the upper limit of the norm, which indicates a significant sympathetic influence on the heart rate. The normal range of the SI parameter lies within the limits of 80-150. Ambient temperature is a major factor affecting the living organism. Many authors have found that the HRV depends on ambient temperature [25-28]. Ren et al. (2011) showed that higher ambient temperature was associated with decreases in the HRV parameters (standard deviation of normal-to-normal intervals, low-frequency power and high-frequency power) during the warm season but not during the cold season [14]. Wu et al. (2013) found nonlinear relationships between the temperature and HRV indices in both the warm and cold seasons [29].

We have shown that, given similar indoor air temperature, there were significant differences in the HRV parameters in the examined groups in winter. We assumed that significant changes in the HRV parameters among the EMERCOM workers and the lack of significant changes in the case of the scientific workers were observed due to the different duration of cold exposure. The average time of the environmental 
exposure during working hours for the EMERCOM inspectors was approx. $3 \mathrm{~h}$ and in the case of the scientific workers, it was approx. $30 \mathrm{~min}$. It is known that cold temperature increases sympathetic tone and increases secretion of catecholamines [30]. In summer with its warm temperature, the differences in the exposure to the environmental factors failed to influence the HRV parameters.

Thus, we assume that the outdoor temperature and duration of its exposure on human are the main factors affecting the regulation of the heart rate variability among men in the winter.

\section{CONCLUSIONS}

In our study we have observed statistically significant seasonal differences in the HRV indices for the EMERCOM workers but not for the scientific workers. We believe that was mainly caused by the different working conditions in groups under study. The EMERCOM workers had more contact with the external environment than the scientific workers. Prolonged exposure to cold air in the case of the EMERCOM workers resulted in the activation of the sympathetic nervous system.

\section{REFERENCES}

1. Barrington WW, Angle CR, Willcockson NK, Padula MA, Korn T. Autonomic function in manganese alloy workers. Environ Res. 1998;78(1):50-8.

2. Jhun HJ, Yim SH, Kim R, Paek D. Heart-rate variability of carbon disulfide-poisoned subjects in Korea. Int Arch Occup Environ Health. 2003;76(2):156-60.

3. PorębaR,PorębaM,GaćP,Steinmetz-BeckA,BeckB,PileckiW, et al. Electrocardiographic changes in workers occupationally exposed to lead. Ann Noninvasive Electrocardiol. 2011;16(1): 33-40, http://dx.doi.org/10.1111/j.1542-474X.2010.00406.x.

4. Bortkiewicz A, Gadzicka E, Szymczak W, Zmyślony M. Heart rate variability (HRV) analysis in radio and TV broadcasting stations workers. Int J Occup Med Environ Health. 2012;25(4): 446-55, http://dx.doi.org/10.2478/s13382-012-0059-x.
5. Karita K, Nakao M, Nishikitani M, Nomura K, Yano E. Autonomic nervous activity changes in relation to the reporting of subjective symptoms among male workers in an information service company. Int Arch Occup Environ Health. 2006;79(5):441-4, http://dx.doi.org/10.1007/s00420-005-0062-7.

6. Malmberg B, Persson R, Flisberg P, Ørbaek P. Heart rate variability changes in physicians working on night call. Int Arch Occup Environ Health. 2011;84(3):293-301, http:// dx.doi.org/10.1007/s00420-010-0593-4.

7. Chung MH, Kuo TB, Hsu N, Chu H, Chou KR, Yang CC. Sleep and autonomic nervous system changes - Enhanced cardiac sympathetic modulations during sleep in permanent night shift nurses. Scand J Work Environ Health. 2009;35(3):180-7, http://dx.doi.org/10.5271/sjweh.1324.

8. Sasaki T, Iwasaki K, Oka T, Hisanaga N. Association of working hours with biological indices related to the cardiovascular system among engineers in a machinery manufacturing company. Ind Health. 1999;37(4):457-63, http:// dx.doi.org/10.2486/indhealth.37.457.

9. Kageyama T, Nishikido N, Kobayashi T, Kurokawa Y, Kaneko T, Kabuto M. Self-reported sleep quality, job stress, and daytime autonomic activities assessed in terms of short-term heart rate variability among male white-collar workers. Ind Health. 1998;36(3):263-72, http://dx.doi.org/10.2486/indhealth.36.263.

10. Lucini D, Riva S, Pizzinelli P, Pagani M. Stress management at the worksite: Reversal of symptoms profile and cardiovascular dysregulation. Hypertension. 2007;49(2):291-7, http:// dx.doi.org/10.1161/01.HYP.0000255034.42285.58.

11. Vrijkotte TG, van Doornen LJ, de Geus EJ. Effects of work stress on ambulatory blood pressure, heart rate, and heart rate variability. Hypertension. 2000;35(4):880-6, http:// dx.doi.org/10.1161/01.HYP.35.4.880.

12. Kristal-Boneh E, Froom P, Harari G, Malik M, Ribak J. Summer-winter differences in $24 \mathrm{~h}$ variability of heart rate. J Cardiovasc Risk. 2000;7(2):141-6.

13. Kristiansen J, Olsen A, Skotte JH, Garde AH. Reproducibility and seasonal variation of ambulatory short-term heart rate variability in healthy subjects during a self-selected rest 
period and during sleep. Scand J Clin Lab Invest. 2009;69(6): 651-61, http://dx.doi.org/10.3109/00365510902946984.

14. Ren C, O’Neill MS, Park SK, Sparrow D, Vokonas P, Schwartz J. Ambient temperature, air pollution, and heart rate variability in an aging population. Am J Epidemiol. 2011;173(9):1013-21, http://dx.doi.org/10.1093/aje/kwq477.

15. Baevsky RM, Berseneva AP. [Introduction in prenosological diagnostics]. Moscow: Slovo; 2008. Russian.

16. Baevskii RM. Analysis of heart rate variability in space medicine. Human Physiol. 2002;28(2):202-13, http://dx.doi. org/10.1023/A:1014866501535.

17. Heart rate variability. Standards of measurement, physiological interpretation, and clinical use. Task Force of the European Society of Cardiology and the North American Society of Pacing and Electrophysiology. Eur Heart J. 1996;17(3):354-81.

18. Millis RM, Austin RE, Hatcher MD, Bond V, Faruque MU, Goring KL, et al. Association of body fat percentage and heart rate variability measures of sympathovagal balance. Life Sci. 2010;86(5-6):153-7, http://dx.doi.org/10.1016/j.lfs.2009.11.018.

19. Ramaekers D, Ector H, Aubert AE, Rubens A, van de WerfF. Heart rate variability and heart rate in healthy volunteers. Is the female autonomic nervous system cardioprotective? Eur Heart J. 1998;19(9):1334-41, http://dx.doi.org/10.1053/ euhj.1998.1084.

20. Dietrich DF, Schindler C, Schwartz J, Barthélémy JC, Tschopp JM, Roche F, et al. Heart rate variability in an ageing population and its association with lifestyle and cardiovascular risk factors: Results of the SAPALDIA study. Europace. 2006;8(7):521-9, http://dx.doi.org/10.1093/europace/eul063.

21. Fagard RH. A population-based study on the determinants of heart rate and heart rate variability in the frequency domain. Verh K Acad Geneeskd Belg. 2001;63(1):57-89.

22. Antelmi I, de Paula RS, Shinzato AR, Peres CA, Mansur AJ, Grupi CJ. Influence of age, gender, body mass index, and functional capacity on heart rate variability in a cohort of subjects without heart disease. Am J Cardiol. 2004;93(3): 381-5, http://dx.doi.org/10.1016/j.amjcard.2003.09.065.

23. Ziegler D, Piolot R, Strassburger K, Lambeck H, Dannehl K. Normal ranges and reproducibility of statistical, geometric, frequency domain, and non-linear measures of 24-hour heart rate variability. Horm Metab Res. 1999;31(12):672-9, http://dx.doi.org/10.1055/s-2007-978819.

24. Sato M, Kanikowska D, Iwase S, Shimizu Y, Nishimura N, Inukai $\mathrm{Y}$, et al. Seasonal differences in melatonin concentrations and heart rates during sleep in obese subjects in Japan. Int J Biometeorol. 2013;57(5):743-8, http://dx.doi. org/10.1007/s00484-012-0601-3.

25. Kinugasa H, Hirayanagi K. Effects of skin surface cooling and heating on autonomic nervous activity and baroreflex sensitivity in humans. Exp Physiol. 1999;84(2):369-77, http:// dx.doi.org/10.1111/j.1469-445X.1999.01839.x.

26. Lan L, Lian Z, Pan L. The effects of air temperature on office workers' well-being, workload and productivity-evaluated with subjective ratings. Appl Ergon. 2010;42(1):29-36, http://dx.doi.org/10.1016/j.apergo.2010.04.003.

27. Liu W, Lian Z, Liu Y. Heart rate variability at different thermal comfort levels. Eur J Appl Physiol. 2008;103(3):361-6, http://dx.doi.org/10.1007/s00421-008-0718-6.

28. Yao Y, Lian Z, Liu W, Jiang C, Liu Y, Lu H. Heart rate variation and electroencephalograph - The potential physiological factors for thermal comfort study. Indoor Air.2009;19(2):93-101,http://dx.doi.org/10.1111/j.1600-0668. 2008.00565.x.

29. Wu S, Deng F, Liu Y, Shima M, Niu J, Huang Q, et al. Temperature, traffic-related air pollution, and heart rate variability in a panel of healthy adults. Environ Res. 2013;120:82-9, http://dx.doi.org/10.1016/j.envres.2012.08.008.

30. Rosenthal T. Seasonal variations in blood pressure. Am J Geriatr Cardiol. 2004;13(5):267-72, http://dx.doi. org/10.1111/j.1076-7460.2004.00060.x.

This work is available in Open Access model and licensed under a Creative Commons Attribution-NonCommercial 3.0 Poland License - http://creativecommons.org/ licenses/by-nc/3.0/pl/deed.en. 